\title{
Identification of antibiotic resistance patterns in Helicobacter pylori strains isolated from gastric biopsies using real-time PCR and genotypic analysis
}

\author{
Juanita Ann Spiteria ${ }^{2}$, Graziella Zahraa ${ }^{a}$ John Schembrib ${ }^{b}$ Anthea Pisani ${ }^{b}$, Elaine Borgc, Neville Spiteric, \\ Eliezer Zahra Bianco ${ }^{b}$, Paul Caruana ${ }^{a}$, James Gauci ${ }^{b}$, Martina Muscat ${ }^{b}$, Christopher Barbaraa, Pierre Ellul $^{\mathrm{b}}$ \\ Mater Dei Hospital, Msida, Malta
}

\section{Abstract}

\begin{abstract}
Background Helicobacter pylori (H. pylori) is associated with dyspepsia, mucus-associated lymphoid tissue lymphoma, gastritis, and peptic ulcer disease. Treatment in Malta consists of triple therapy, which consists of a proton pump inhibitor and 2 of the antibiotics amoxicillin, clarithromycin, metronidazole and fluoroquinolones. We aimed to determine the resistance rates for clarithromycin and fluoroquinolones in patients with $\mathrm{H}$. pylori, and its incidence, in patients undergoing an esophagogastroduodenoscopy (EGD) using real-time polymerase chain reaction (RT-PCR).
\end{abstract}

Methods Patients undergoing an EGD were recruited. A rapid urease test (RUT) was performed, and 4 gastric biopsies were also taken (2 from antrum, 2 from corpus) and analyzed using RT-PCR. Positive samples were tested for antibiotic resistance using amplification and reverse hybridization techniques.

Results Two hundred patients (mean age 53.6 [range 20-92] years; 53.1\% female) were recruited; the majority were $(78 \%)$ non-smokers. H. pylori was identified in $21.0 \%$ of the patients. Fluoroquinolone resistance was detected in $21.4 \%$ of the patients. Clarithromycin resistance was observed in $26.2 \%$, with dual resistance identified in $4.8 \%$ of the patients. A high concordance was present with patients testing negative for H. pylori with both RUT and RT-PCR (94.3\%). Only 57.6\% of patients tested positive with both tests. However, $92.9 \%$ of RT-PCR positive patients had a positive genotype HelicoDR test.

Conclusions This data demonstrates a high rate of $H$. pylori resistance to both clarithromycin and fluoroquinolones. These should be avoided when treating $H$. pylori by utilizing different treatment regimes. Furthermore, we derived important data on the role of RT-PCR, which may be implemented in routine clinical practice.

Keywords Helicobacter pylori, antibiotic resistance, clarithromycin, fluoroquinolones, genotype HelicoDR

Ann Gastroenterol 2021; 34 (1): 1-9

\section{Introduction}

Helicobacter species are Gram-negative helical-shaped micro-organisms. Helicobacter pylori (H. pylori) has the highest

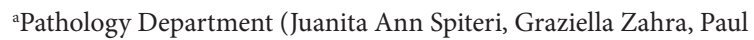
Caruana); ${ }^{\mathrm{b}}$ Department of Medicine (John Schembri', Anthea Pisani, Eliezer Zahra Bianco, James Gauci, Martina Muscat, Pierre Ellul); 'Department of Surgery (Elaine Borg, Neville Spiteri), Mater Dei Hospital, Msida, Malta

Conflict of Interest: None

Correspondence to: Juanita Zahra Bianco, Mater Dei Hospital, Level 2, Block B, Pathology Department, Bacteriology Laboratory, Triq Dun Karm L-Imsida, MSD 2090, Malta, e-mail: juanita_spiteri@yahoo.co.uk

Received 16 July 2020; accepted 1 February 2021; published online 2 April 2021

DOI: https://doi.org/10.20524/aog.2021.0624 clinical importance [1], as it leads to intestinal metaplasia and dysplasia [2]. It is classified as a Class 1 carcinogen [3].

Empirical treatment according to hospital guidelines consisted of clarithromycin triple therapy for 10-14 days. This consists of a proton pump inhibitor (PPI), clarithromycin, and amoxicillin or metronidazole. It is recommended in regions where clarithromycin resistance is known to be $<15 \%$ for H. pylori and for patients with no recent macrolide exposure. In areas where resistance is higher, or patients have been treated with macrolides, bismuth-based quadruple therapy (BQT) is recommended. BQT consists of a PPI, bismuth, tetracycline, and a nitroimidazole for the same duration and can be considered as a first-line treatment.

In regions with high clarithromycin and metronidazole resistance rates and where bismuth would not be available, prescribed regimes include non-bismuth quadruple therapies (amoxicillin, tetracycline, rifabutin and furazolidone), sequential therapy (PPI and amoxicillin, followed by a PPI, 
clarithromycin and a nitroimidazole), and hybrid therapy (PPI and amoxicillin followed by a PPI, amoxicillin, clarithromycin and a nitroimidazole) [4].

Eradication failures are encountered primarily due to antibiotic resistance [5]. Although H. pylori exhibits low resistance to amoxicillin [6], resistance to clarithromycin and fluoroquinolones is increasing. This can be attributed to the overuse of antibiotics for other infections [7,8]. Resistance to metronidazole can be overcome by increasing the dosage, duration and frequency of treatment [4]. The long-lasting nature of $H$. pylori infection in the gastric mucosa makes it susceptible to antibiotics that can attain high concentrations in the gastric mucosa for an extended duration [9]. Thus, the World Health Organization has classified it as a priority Group 2 organism for drug development [10].

Locally, treatment failures have been observed. No studies about antibiotic resistance patterns in $H$. pylori had ever been conducted and there was a lack of knowledge about resistance. Current regional practice for the management of $H$. pylori adopts the "test and treat" strategy. Identification of $H$. pylori infection is performed through the rapid urease test (RUT) at endoscopy. Clarithromycin-based triple therapy is prescribed with positive results, whilst metronidazole and levofloxacin are second-line drugs. Any false-positive results lead to unnecessary costs and increased drug resistance.

The primary aims of this study were to: 1) determine primary resistance rates for clarithromycin and/or fluoroquinolones in $H$. pylori strains using reverse hybridization techniques; and 2) determine the incidence of $H$. pylori in Maltese patients undergoing an esophagogastroduodenoscopy (EGD) using real-time polymerase chain reaction (RT-PCR). The secondary objective for this study was to analyze any differences in detection when using the RUT test at endoscopy versus RTPCR for H. pylori DNA in gastric biopsies.

\section{Patients and methods}

\section{Patient selection, data collected and ethics}

Patients attending the Endoscopy Unit were prospectively recruited and patient consent was obtained prior to the study. The main inclusion criterion was age 16 years or above. All patients were of Caucasian race. Exclusion criteria were: previous testing and/or treatment for $H$. pylori and use of antibiotics in the preceding 3 months. The presence of $H$. pylori DNA detected during testing was another inclusion criterion. Four gastric biopsies were collected per patient, 2 from the antrum and 2 from the corpus. A further 2 samples were collected for the RUT, one from the antrum and one from the body. Samples from the antrum were taken $5 \mathrm{~cm}$ proximal to the pylorus [11]. Biopsies were placed in $3 \mathrm{~mL}$ of $0.9 \%$ sterile saline in a sterile glass tube. All biopsies were kept at $4^{\circ} \mathrm{C}$ until processed. Data collected included age, sex, smoking status, excess intake of alcohol, intake of PPIs, and the result of the RUT. Indications for endoscopy are included in Table 1. The study was performed from February till September 2018.
Table 1 Indications for esophagogastroduodenoscopy

\begin{tabular}{lc}
\hline Indication & $\mathrm{n}=\%$ \\
\hline Dyspepsia & 47 \\
GERD & 28 \\
Iron deficiency anemia & 15.5 \\
Weight loss & 5 \\
Dysphagia & 1 \\
Work up for celiac disease & 3.5 \\
Total & 100 \\
\hline GERD, gastroesophageal reflux disease &
\end{tabular}

Ethical approval had been obtained from the University of Malta Research Ethics committee in November 2017.

\section{Tissue digestion}

All 4 biopsies were combined in a $1.5 \mathrm{~mL}$ micro-centrifuge tube to which $180 \mu \mathrm{L}$ of tissue lysing buffer - Buffer ATL supplied $\left(\right.$ QIAGEN ${ }^{\circledR}$ ) were added. Samples were vortexed for $10 \mathrm{sec}$ with subsequent addition of $20 \mu \mathrm{L}$ of Proteinase $\mathrm{K}$ and vortex. All processed biopsies were stored at $56^{\circ} \mathrm{C}$ for a minimum of $48 \mathrm{~h}$. Occasional vortex was also required during incubation to encourage lysis. All digested samples were stored at $4^{\circ} \mathrm{C}$ until further processing [12].

\section{DNA extraction}

Automated DNA extraction using the Qiagen QIAcube was done using the standardized tissue protocol of the QIAamp DNA mini kit (Qiagen Germany) [12]. All samples were reheated to $56^{\circ} \mathrm{C}$ to allow Buffer ATL precipitates to dissolve. Samples were vortexed for $15 \mathrm{sec}$ and $200 \mu \mathrm{L}$ of the digested sample was pipetted into a second $1.5 \mathrm{~mL}$ micro-centrifuge tube, to which $10 \mu \mathrm{L}$ of an $H$. pylori internal control provided with the RT-PCR kit was added. Sample lysis was carried out using Proteinase $\mathrm{K}$ and Buffer AL followed by DNA binding and washing. Elution of $100 \mu \mathrm{L}$ of DNA was performed in Buffer AE. All eluted DNA was stored at $-20^{\circ} \mathrm{C}[12]$.

\section{RT- PCR using the Amplisens ${ }^{\circledR}$ H. pylori-FRT PCR kit}

Amplification of genome specific regions in $H$. pylori using appropriate primers allowed identification of $H$. pylori. A master mix was prepared consisting of $10 \mu \mathrm{L}$ of PCR Mix1-FL, $5 \mu \mathrm{L}$ of PCR Mix-2-FRT and $0.5 \mu \mathrm{L}$ of hot-start TaqF polymerase. Hot-StarTaqF polymerase was used to reduce the occurrence of non-specific reactions. Pipetting errors were compensated. DNA used per sample was $10 \mu \mathrm{L}$, leading to a total reaction volume of $25 \mu \mathrm{L}$ per sample.

A positive and negative control were used with every RTPCR run to ensure consistent results. All samples and controls 
were pipetted into $0.1 \mathrm{~mL}$ disposable, capped polypropylene PCR strip tubes. These were loaded onto a Rotor-Disc and placed in the Rotor-Gene-Q (QIAGEN $\left.{ }^{\circledR}\right)$. Fluorescentlabelled probes bound to the amplification product emitted a fluorescent signal, allowing $H$. pylori identification. Positive results were determined if a cycle threshold $(C t)$ value up to 38.00 was obtained. A positive control of amplification was used, while the negative template control consisted only of the reaction mixture [13]. A positive control strain was not utilized as positive and negative controls of amplification always gave consistent results.

\section{Genotype HelicoDr - amplification and reverse hybridization technique for antibiotic resistance in $\mathrm{H}$. pylori}

All RT-PCR positive samples were tested for resistance to clarithromycin and/or fluoroquinolones using the genotype HelicoDr assay $(n=42)$. Mutations - N87K in the Gyr87 codon and mutations D91N, D91G, D91Y responsible for fluoroquinolone resistance in the Gyr91 codon were identified for the GyrA gene. Mutations A2146G, A2146C and $\mathrm{A} 2147 \mathrm{G}$ were identified for the 23srRNA ( $\mathrm{Rrl}$ ) gene responsible for clarithromycin resistance (GenBank Accession Number Nc_000915). DNA extracted was used. Multiplex PCR amplification using supplied biotinylated primers was performed. The amplicon was then used for reverse hybridization.

Reverse hybridization was done at $45^{\circ} \mathrm{C}$ using a vibrating incubator (TwinCubator, Hain Lifescience, Germany). Denaturation of the amplicon and hybridization of the denatured single-stranded biotin-labeled amplicon to membrane-bound DNA probes on coated strips were performed. Subsequent washing with stringent reagent, addition of a streptavidin/ alkaline phosphatase conjugate, and addition of an alkaline phosphatase-mediated substrate allowed bands to become visible. The substrate concentrate was vortexed slightly to achieve a homogenous solution. Sensitivity or resistance of H. pylori to clarithromycin and/or fluoroquinolones was interpreted according to the bands obtained. The intensity of hybridization bands was compared to the amplification control band. Bands with a stronger intensity were interpreted. Only test strips that had both conjugate control and amplification control bands were interpreted, as per standard operating procedures [14].

\section{Statistical analysis}

Based on previous local studies $[15,16]$, the sample size required for $H$. pylori detection within a cohort with a $95 \%$ degree of confidence was determined to be 200 patients. The identification of at least one resistant strain of $H$. pylori in gastric biopsies through genotypic mutations to either one or both antibiotics was enough to satisfy our primary objective. All data, except age, was categorical. Therefore, Pearson's chisquared test was used. Pearson's chi square test was carried out to identify any associations between variables (Table 2). RUT results were compared with RT-PCR results. Age was transformed into a categorical variable by the generation of age groups. A 0.05 level of significance was taken. P-values of $<0.05$ obtained showed that a statistically significant association was present. Fisher's exact test was also used. In addition, descriptive statistical techniques were used to observe associations graphically. Data were analyzed using SPSS software version 22 (IBM, New York, United States) using a Mac OS.

\section{Quality control}

All analyzers used had been previously calibrated according to standard laboratory protocols. All techniques used were validated. Controls were used to ensure valid results. The protocols were performed according to standard operating procedures.

\section{Results}

Two hundred patients were recruited (females: 53.1\%), with $78 \%$ of patients being non-smokers. Excess alcohol intake was observed in $4.1 \%$ of male patients. Fig. 1 demonstrates the patients' characteristics in terms of age, smoking and alcohol consumption. The mean age was 53.6 years ( $\mathrm{SD} \pm 16.3$ years), with the median age being 56 years.

\section{H. pylori detection}

H. pylori was detected in $21.0 \%$ of patients tested by RTPCR. In comparison, $29.5 \%$ of patients had a positive RUT at endoscopy. A positive RUT and a positive RT-PCR result were observed in $17.0 \%$ of patients, while $12.5 \%$ of patients had a positive RUT result but a negative RT-PCR result and $4.0 \%$ had a negative RUT but a positive RT-PCR. H. pylori detected by RT-PCR was again detected by the genotype HelicoDR kit in $92.9 \%$ of those patients. In $7.1 \%$ of RT-PCR positive patients, a negative $H$. pylori result was obtained with the genotype HelicoDR kit (Table 3). Incidentally, a negative RUT at endoscopy was also obtained.

\section{Antibiotic resistance in $\mathrm{H}$. pylori}

Among a total of 42 positive patients, wild-type (WT) sensitive $H$. pylori strains were detected in $50.0 \%$ of patients. Total clarithromycin resistance was detected in $26.2 \%$ of positive patients and total fluoroquinolone resistance in $21.4 \%$ (Table 4). Heterogeneous strains were detected in $26.2 \%$ of positive patients, as more than one hybridization band was detected with both genes tested. Hetero-resistance was also observed. This signifies the strain being tested was expressing both WT and mutated bands, or that the patient was infected with more than one strain of $H$. pylori. Table 4 
Table 2 Demographic features of Helicobacter pylori (H. pylori)-positive patients

\begin{tabular}{|c|c|c|c|c|c|}
\hline \multirow[t]{2}{*}{ Independent variable } & \multirow[t]{2}{*}{ Demographics } & \multirow[t]{2}{*}{ Total Subjects tested } & \multicolumn{2}{|c|}{ H. pylori } & \multirow[t]{2}{*}{ P-value } \\
\hline & & & Positive (\%) & Negative (\%) & \\
\hline \multirow[t]{5}{*}{ Age } & & & & & 0.067 \\
\hline & 40 years or less & 48 & $6(14.3)$ & $42(26.6)$ & \\
\hline & 41-55 years & 50 & $7(16.7)$ & $43(27.2)$ & \\
\hline & $56-65$ years & 46 & $14(33.3)$ & $32(20.3)$ & \\
\hline & 66 or more years & 56 & $15(35.7)$ & $41(25.9)$ & \\
\hline \multirow[t]{3}{*}{ Sex } & & & & & 0.797 \\
\hline & Male & 94 & $19(20.2)$ & $75(79.8)$ & \\
\hline & Female & 106 & $23(21.7)$ & $83(78.3)$ & \\
\hline \multirow[t]{4}{*}{ Smoking status } & & & & & 0.020 \\
\hline & Non-Smoker & 156 & $27(17.3)$ & $129(82.7)$ & \\
\hline & Smoker & 26 & $7(26.9)$ & $19(73.1)$ & \\
\hline & Ex-Smoker & 18 & $8(44.4)$ & $10(55.6)$ & \\
\hline \multirow[t]{3}{*}{ Excess alcohol intake } & & & & & 0.003 \\
\hline & Yes & 8 & $5(62.5)$ & $3(37.5)$ & \\
\hline & No & 192 & $37(19.3)$ & $155(80.7)$ & \\
\hline \multirow[t]{3}{*}{ Rapid urease test } & & & & & $<0.001$ \\
\hline & Positive & 59 & $34(57.6)$ & $25(42.4)$ & \\
\hline & Negative & 141 & $8(5.7)$ & $133(94.3)$ & \\
\hline \multirow[t]{3}{*}{ Use of PPIs } & & & & & 0.453 \\
\hline & Yes & 104 & $24(23.1)$ & $80(76.9)$ & \\
\hline & No & 96 & $18(18.8)$ & $78(81.3)$ & \\
\hline
\end{tabular}

PPIs, proton pump inhibitors

Table 3 Correlation of results between different methods of testing for Helicobacter pylori (H. pylori) identification

\begin{tabular}{lcc}
\hline Type of test & $\begin{array}{c}\text { Total number of } \\
\text { patients (n=200) }\end{array}$ & Percentage (\%) \\
\hline $\begin{array}{l}\text { RUT positive and H. pylori } \\
\text { RT-PCR positive }\end{array}$ & 34 & 17.0 \\
$\begin{array}{l}\text { RUT positive and } H \text {. pylori } \\
\text { RT-PCR negative }\end{array}$ & 25 & 12.5 \\
$\begin{array}{l}\text { RUT negative and } H \text {. pylori } \\
\text { RT-PCR positive }\end{array}$ & 8 & 4.0 \\
$\begin{array}{l}\text { RUT negative and } H \text {. pylori } \\
\text { RT-PCR negative }\end{array}$ & 133 & 66.5 \\
\hline & Total number of & Percentage (\%) \\
& patients (n=42) \\
\hline $\begin{array}{l}\text { RT-PCR positive and } \\
\text { genotype HelicoDR positive }\end{array}$ & 39 & 92.9 \\
$\begin{array}{l}\text { RT-PCR positive and } \\
\text { genotype HelicoDR negative }\end{array}$ & 3 & 7.1 \\
\hline RUT, rapid urease test; $R T$-PCR, real-time polymerase chain reaction
\end{tabular}

shows the percentage of hetero-resistant strains detected for clarithromycin and fluoroquinolones.

\section{Genotype detection}

Sensitivity or resistance was determined using the genotype HelicoDR molecular assay. This analysis of the Gyr87 and Gyr91 codon in the GyrA gene identified fluoroquinolone resistance. The most common allele for Gyr87, identified in 20 patients, was WT-1, showing sensitivity to fluoroquinolones. Three mutation probes, mutation 1 - D91N, mutation 2 - D91G and mutation 3 D91Y, were also identified for Gyr91.

Sensitivity or resistance to clarithromycin is identified through mutations in the 23srRNA gene. The WT band for the 23s rRNA gene indicating sensitivity to clarithromycin was identified in 34 patients. Mutation band 3 (mutation A2147G) for clarithromycin resistance was the most common allele. Fig. 2 and Table 4 show the genotypes detected in all of our patient cohort. Information related to genotypes detected is interpreted in comparison to age groups and sex.

H. pylori was found in patients who were either smokers (26.9\%) or ex-smokers (44.4\%), significantly more frequently than in non-smokers $(17.3 \%)(\mathrm{P}=0.020)$ (Table 2). From our total patient cohort who consumed excess alcohol $(\mathrm{n}=8)$, $62.5 \%$ tested positive for $H$. pylori $(n=5)$. Statistically, this was significantly higher than $H$. pylori-positive patients who 
Table 4 Tabulation of different genotypes detected showing antibiotic resistance patterns between sexes and age groups

\begin{tabular}{|c|c|c|c|c|c|c|}
\hline Genotype detected & & $\begin{array}{l}\text { H. pylori+ve } \\
\text { patients }(\mathrm{n}=42)\end{array}$ & Percentage (\%) & $\begin{array}{l}\text { Male } \\
(\mathrm{n}=42)\end{array}$ & $\begin{array}{l}\text { Female } \\
(\mathrm{n}=42)\end{array}$ & $\begin{array}{l}\text { Mean age of } \\
\text { patients in years }\end{array}$ \\
\hline Sensitive H. pylori strains & & 21 & 50 & 10 & 11 & 57.3 \\
\hline Total clarithromycin resistance & & 11 & 26.2 & 3 & 8 & 63.5 \\
\hline A2146G & MUT1 & 3 & 7.1 & 1 & 2 & 54.3 \\
\hline A2146C & MUT2 & 2 & 4.8 & 0 & 2 & 71.5 \\
\hline A2147G & MUT3 & 7 & 16.7 & 2 & 5 & 66.6 \\
\hline $\mathrm{A} 2146 \mathrm{C}+\mathrm{A} 2147 \mathrm{G}$ & MUT2+MUT3 & 1 & 2.4 & 0 & 1 & 73 \\
\hline Hetero-resistance to clarithromycin & & 6 & 14.3 & 2 & 4 & 61.7 \\
\hline Total fluoroquinolone resistance & & 9 & 21.4 & 4 & 5 & 58.4 \\
\hline N87K & GyrA 87 MUT & 3 & 7.1 & 1 & 2 & 42.3 \\
\hline D91N & GyrA 91 MUT 1 & 3 & 7.1 & 0 & 3 & 63.7 \\
\hline D91G & MUT 2 & 1 & 2.4 & 1 & 0 & 81 \\
\hline D91K & MUT 3 & 2 & 4.8 & 2 & 0 & 65 \\
\hline Hetero-resistance to fluoroquinolones & & 4 & 9.5 & 2 & 2 & 52.5 \\
\hline $\begin{array}{l}\text { Dual resistance to clarithromycin and } \\
\text { fluoroquinolones }\end{array}$ & & 2 & 4.8 & 1 & 1 & 68.5 \\
\hline H. pylori negative by genotype HelicoDr & & 3 & 7.1 & 3 & 0 & 59.3 \\
\hline
\end{tabular}

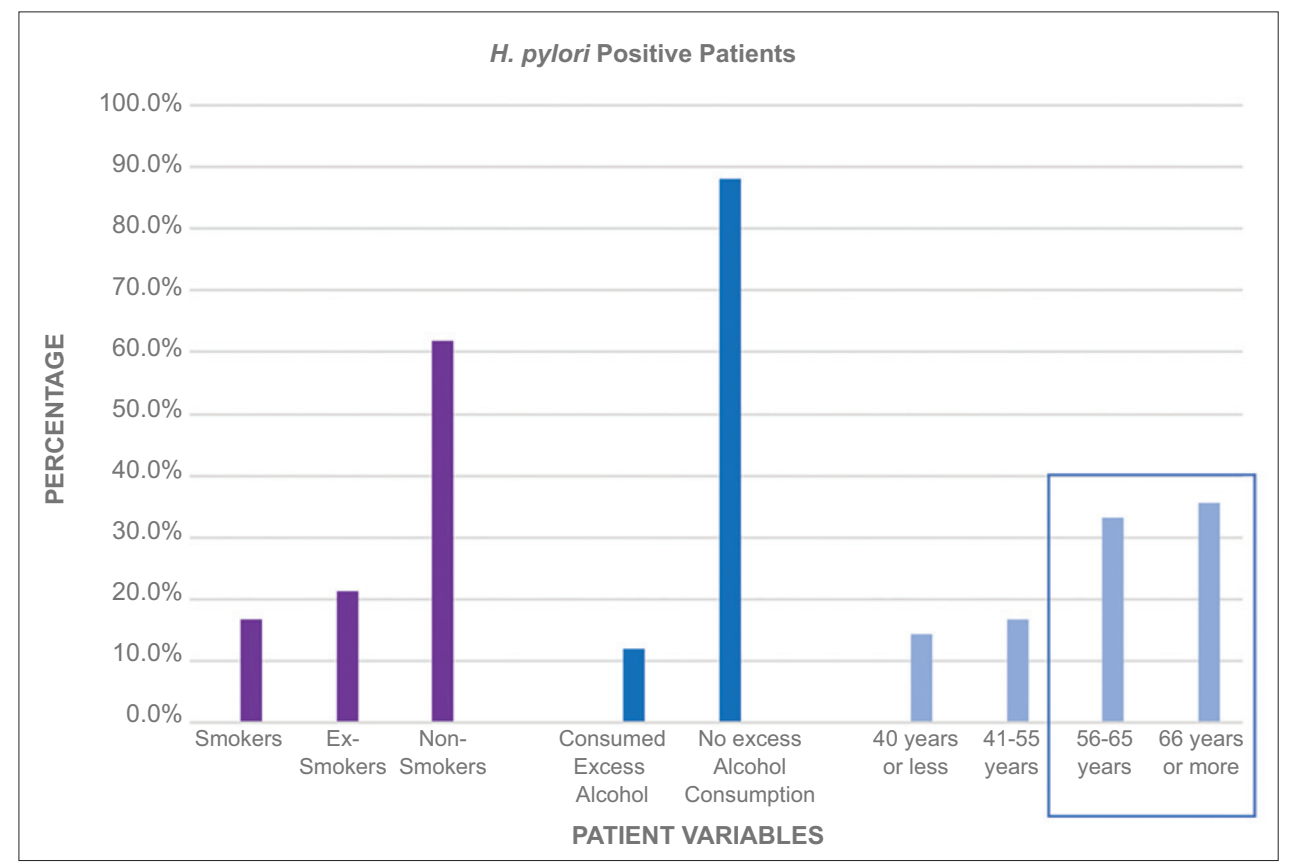

Figure 1 Patient demographics. Graph showing the characteristics of the patients with regards to age, smoking status and alcohol consumption

did not consume excess alcohol ( $\mathrm{n}=37 / 200 ; 19.3 \% ; \mathrm{P}=0.003)$, (Table 2).

When comparing the results of the RUT with results from RT-PCR, a negative result was obtained in $94.3 \%$ of total patients tested. Positive RT-PCR results were also compared with the RUT results, and only $57.6 \%$ of patients had a positive result with both tests. The remainder either had a positive RTPCR result and a negative RUT result, or a positive RUT with a negative RT-PCR result. However, a statistically significant association was still found between both tests $(\mathrm{P}<0.001)$ (Table 2).

H. pylori was present in $21.7 \%$ of females and $20.2 \%$ of males $(\mathrm{P}=0.797)$. No sex-related difference was detected. The highest percentage of $H$. pylori positive results was obtained in patients over 66 years old (35.7\%). Patients below the age of 40 years had the lowest percentage $(14.3 \%)$. Fisher's test also 


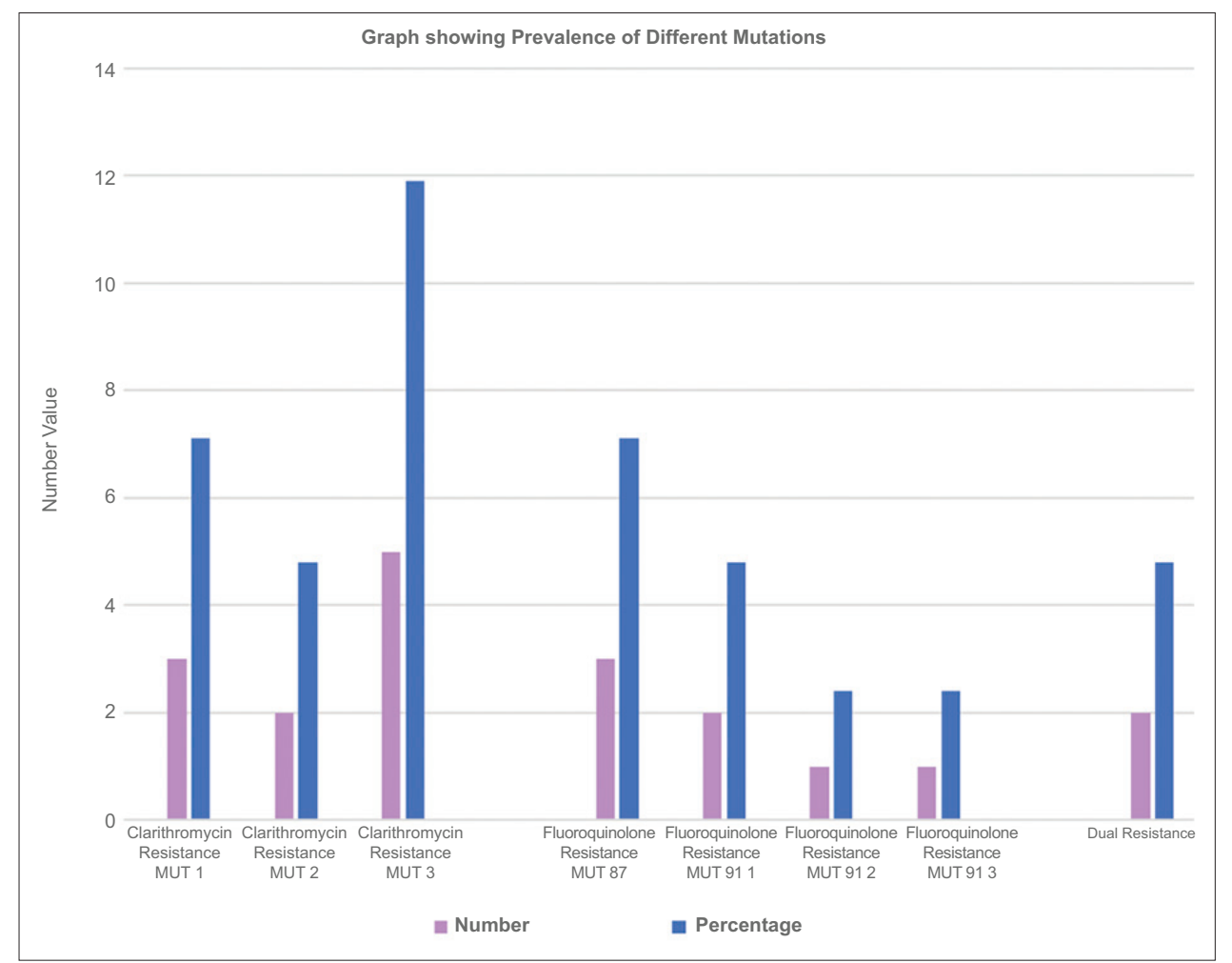

Figure 2 Prevalence of different mutations. The different mutations for clarithromycin and fluoroquinolne resistance as detected in Helicobacter pylori-positive patients

showed that patients above the age of 55 years were more likely to have $H$. pylori infection with antibiotic resistance $(\mathrm{P}=0.0264)$ (Table 4). No statistically significant association was observed between intake of PPIs and detection of $H$. pylori through RT$\operatorname{PCR}(\mathrm{P}=0.453)$.

\section{Discussion}

Our study demonstrated that the prevalence of $H$. pylori among patients who require an EGD was $21 \%$. Among patients who tested positive for $H$. pylori, $26.2 \%$ exhibited resistance to clarithromycin while a further $21.4 \%$ exhibited resistance to fluoroquinolones. A small percentage, $4.8 \%$, exhibited resistance to both antimicrobials.

The prevalence of $H$. pylori in our cohort correlates with local data from 2009, which had demonstrated a prevalence of $38 \%$ from histology and RUT [15]. A 2017 study using only RUT also demonstrated a $15 \%$ prevalence [16]. This study also demonstrated that prevalence increased with age, being highest in those above 66 years of age. This mirrors data from international studies $[17,18,19]$ and the above supports the validity of our study. Although resistance was more common in people above 55 years, this was not statistically significant. Eighty percent $(80 \%)$ of patients who were resistant to fluoroquinolones were in the 56-65 age group, while $66.7 \%$ of patients resistant to clarithromycin were above 66 [20]. Furthermore, no association between the use of PPIs and antibiotic resistance was observed. However, it is thought that the use of high dosage PPIs could improve eradication rates, although this was found to be more effective in highmetabolizing PPI patients [4].

The RUT is an efficient way to determine the presence or absence of $H$. pylori infection [21]. In our study, $42.4 \%$ of the total positive RUT observed at endoscopy had a negative result with RT-PCR. Locally, all positive RUTs are treated empirically. Hence, these patients may be treated unnecessarily. A possible reason for this is not following the manufacturer's instructions and reading the RUT late [21]. However, in our study we made sure that the specific instructions were followed. The presence of other urease-producing organisms, such as members of Enterobacterales, or Staphylococcus aureus, can produce a falsepositive RUT [4]. Meanwhile the use of PPIs or the presence of blood can give false-negative results. Use of antibiotics might have led to false-negative RUT results; however, all patients were questioned thoroughly regarding recent antibiotic usage. Additionally, $5.7 \%$ of all negative RUT results had a positive RTPCR result. This signifies that these patients were potentially infected and not treated. The use of PPIs prior to endoscopy can also lead to a negative RUT and histology result. This is not the case with molecular techniques [22,23].

Interestingly, 3 of the patients with a positive RT-PCR result but a negative RUT had a very high $C t$ value with RT-PCR (35.85, 34.46 and 37.07 , respectively). Such high values signify a low bacterial load. This explains the negative RUT, as a minimum of 10,000 organisms is required [21]. Specimens tested by RT-PCR were taken from adjacent to those tested by RUT. These patients 
also had a negative result with the genotype HelicoDR kit, suggesting that this assay might have a higher limit of detection, even though no international data are available. Considering the incidence of false-positive and false-negative results, the identification of $H$. pylori should be based on 2 or more tests $[21,24]$. However, the positive correlation between the RT-PCR and genotype HelicoDR suggests that the former test may be a more appropriate and reliable test to perform during endoscopy.

H. pylori was found in smokers and ex-smokers statistically more frequently than in non-smokers $(\mathrm{P}=0.020)$. International data regarding smoking are conflicting, with only some studies confirming this association [25-30]. Though one might note a significant association between excessive intake of alcohol and prevalence of $H$. pylori infection, one should consider that there were only 8 patients who consumed excess alcohol. This represents a significant bias. There are dissimilarities in the literature regarding the effects of excess alcohol [31,32].

Culture of $H$. pylori is not routine at our laboratory. Furthermore, it is laborious to grow and specific transport conditions are required [22,30]. The use of the genotype HelicoDR molecular assay allowed the identification of $H$. pylori and its genotypic expression of resistance. Genotype HelicoDr has a higher sensitivity (80.3\%) and specificity (75.0\%) when compared to culture, and comparable sensitivity (74.2\%) and specificity (75.0\%) when compared to histology [33]. Genotypic expression was not compared to phenotypic expression of resistance in this study; however, studies report a good correlation [34,35].

The advantage of culture lies in the identification of resistance to other antimicrobials, including metronidazole, amoxicillin and tetracyclines [34], whilst the identification of hetero-resistant strains is easier to detect via molecular techniques [22]. Our results have indicated the presence of hetero-resistance to both antimicrobials in several patients. Hetero-resistance is important, as it can show either the presence of 2 different populations of $H$. pylori, with different sensitivities, or the same strain expressing both the normal gene and the mutation. In the first scenario, H. pylori is partially eradicated.

Current guidance suggests avoiding the prescription of clarithromycin in areas where resistance levels are higher than $15 \%$ [4]. Our findings indicate high levels of primary resistance to both clarithromycin (26.2\%) and fluoroquinolones (21.4\%), suggesting that the use of standard empirical triple therapy should be altered. Our data correlate with a recent meta-analysis stating that resistance to clarithromycin and levofloxacin has increased worldwide [36,37]. Data from North America demonstrate resistance rates of approximately $30 \%$ for both antibiotics [6,37].

Studies suggest that therapy regimens should be tailored based on genotypic results. This has exhibited an eradication rate of more than $80 \%$. Patients who exhibit only the WT strain for both the 23s rRNA ( Rrl) and the Gyr alleles would be eligible for empirical triple therapy treatment $[39,40]$. Patients who exhibit mutations in the 23s rRNA $(R r l)$ allele but WT strains for the Gyr allele would be eligible for firstline fluoroquinolone-based therapies. Patients who exhibit dual resistance would be eligible for other non-clarithromycin and non-fluoroquinolone therapies, or a salvage regimen containing amoxicillin and rifabutin or a PPI for 10-days [41]. In our study, 42 patients were positive for $H$. pylori DNA with RT-PCR. Eighteen patients showed resistance to either clarithromycin or fluoroquinolones or both, whilst a further 3 patients gave a negative $H$. pylori result. Thus, $42.8 \%$ of our tested population showed resistance, and, if treated with therapies containing either/or of these antibiotics, they would not exhibit an eradication rate of more than $80 \%$. Therefore, it can be concluded that only $50 \%$ of our $H$. pylori positive patients can be treated safely with such therapies, assuming our patients are to have more than $80 \%$ chance of total recovery.

Based on the above, it would be wiser to eliminate clarithromycin-based therapies and utilize non-bismuth quadruple concomitant therapy or BQT. Only concomitant therapy can be prescribed in Malta, as bismuth compound is not available for treatment. Although clarithromycin is present, the presence of a nitroimidazole would still render the treatment effective. Though metronidazole resistance levels are not known in Malta, and were not within the scope of study in this analysis, metronidazole resistance can be overcome by increasing treatment dosage, dosing interval and duration [4].

Several limitations were encountered during this study. Recruitment was difficult, owing primarily to the small Maltese population and previous exposure to antibiotics in the preceding 3 winter months, leading to their exclusion. We also did not analyze all patients with all 3 methods (RUT, RT-PCR and genotype HelicoDR). Further validation of the RT-PCR in detection of $H$. pylori would need to be used in conjunction with RUT, genotype HelicoDR, as well as noninvasive testing such as fecal antigen testing. As culture and sensitivity is not routine, this was also a major limitation, as the phenotypic expression of resistance and the corresponding minimal inhibitory concentration of clarithromycin and fluoroquinolones could not be reported. Constraints of funding, time and lack of knowledge about the routine culture of $H$. pylori affected our study, as PCR results could not be confirmed via antibiotic susceptibility testing. Time constraints also precluded the use of the Sydney protocol during biopsy collection.

In conclusion, this study has demonstrated the unknown antibiotic resistance levels of $H$. pylori strains for clarithromycin and fluoroquinolones. Furthermore, testing for $H$. pylori with RT-PCR will allow the correct identification of patients with this infection. This avoids unnecessary prescriptions and identification of previously false-negative patients (RUT and histology) who would have been taking PPIs.

\section{Acknowledgments}

The research study was supported by Mater Dei hospital and the Gastroenterology division. All participants were informed of the study and recruited prior to an esophagogastroduodenoscopy. Gastric biopsies were then collected by various clinicians within the Gastroenterology Division. All molecular techniques were performed at the Molecular Diagnostics Laboratory at Mater Dei Hospital. 


\section{Summary Box}

\section{What is already known:}

- Helicobacter pylori (H. pylori) is statistically more significantly found in patients above 55 years of age. This was also observed in our study $(\mathrm{P}=0.0264)$

- Smokers were more likely to have $H$. pylori than non-smokers $(\mathrm{P}=0.020)$, confirming international literature

- There is an increase in antibiotic resistance to clarithromycin and fluoroquinolones world wide

- Triple therapy should be avoided in areas of high antibiotic resistance as per guidelines stated in the Maastricht V/Florence Consensus Report

\section{What the new findings are:}

- RT-PCR, which is not affected by previous PPI usage, can lead to a higher detection rate due to a higher sensitivity.

- In view of this high antibiotic resistance, testing for other antibiotic resistance needs to be also implemented. This will avoid treatment failures, unnecessary antibiotic prescription and thus a more targeted approach.

- RUT should not be the sole method of identification for the detection of $\mathrm{H}$. pylori as was the procedure. Detection should be based on 2 or more methods of detection to avoid false positive or negative results.

\section{References}

1. Public Health England. UK Standards for Microbiology Investigations. Investigation of infectious causes of dyspepsia. 2019. Available from: https://assets.publishing.service.gov. uk/government/uploads/system/uploads/attachment_data/ file/837458/B_55i7.pdf [Accessed 1 March 2021].

2. Watari J, Chen N, Amenta PS, et al. Helicobacter pylori associated chronic gastritis, clinical syndromes, precancerous lesions, and pathogenesis of gastric cancer development. World J Gastroenterol 2014;20:5461-5473.

3. International Agency for Research on Cancer (IARC). IARC Monographs on the Evaluation of Carcinogenic Risks to Humans, 1994, vol. 94. Available from: https://publications.iarc.fr/79 [Accessed 1 March 2021].

4. Malfertheiner P, Megraud F, O'Morain CA, et al; European Helicobacter and Microbiota Study Group and Consensus panel. Management of Helicobacter pylori infection-the Maastricht V/ Florence Consensus Report. Gut 2017;66:6-30.

5. Chey WD, Leontiadis GI, Howden CW, Moss SF. ACG Clinical Guideline: treatment of Helicobacter pylori infection. Am J Gastroenterol 2017;112:212-239.

6. Thung I, Aramin H, Vavinskaya V, et al. Review article: the global emergence of Helicobacter pylori antibiotic resistance. Aliment Pharmacol Ther 2016;43:514-533.
7. Mégraud F. The challenge of Helicobacter pylori resistance to antibiotics: the comeback of bismuth-based quadruple therapy. Therap Adv Gastroenterol 2012;5:103-109.

8. Mégraud F, Bessède E, Varon C. Helicobacter pylori infection and gastric carcinoma. Clin Microbiol Infect 2015;21:984-990.

9. Megraud F, Coenen S, Versporten A, et al; Study Group participants. Helicobacter pylori resistance to antibiotics in Europe and its relationship to antibiotic consumption. Gut 2013;62:34-42.

10. Tacconelli E, Carrara E, Savoldi A, et al; WHO Pathogens Priority List Working Group. Discovery, research, and development of new antibiotics: the WHO priority list of antibiotic-resistant bacteria and tuberculosis. Lancet Infect Dis 2018;18:318-327.

11. Midolo P, Marshall BJ. Accurate diagnosis of Helicobacter pylori. Urease tests. Gastroenterol Clin North Am 2000;29:871-878.

12. QIAGEN. QIAamp ${ }^{\circledR}$ DNA Mini Kit and QIAamp DNA Blood Mini Kit Handbook 2003. Available from: https://www.qiagen. $\mathrm{com} / \mathrm{us} /$ products/discovery-and-translational-research/dnarna-purification/dna-purification/genomic-dna/qiaamp-dnakits/\#resources/ [Accessed 1 March 2021].

13. Ecoli s.r.o. AmpliSens Helicobacter pylori-FRT PCR kit Instruction Manual 2015. Available from: https://www.pcrdiagnostics.eu/data/ machines/r-b9_rgiq_ce-helicobacter-pylori-frt-210618.pdf

14. Hain Lifescience. GenoType HelicoDR 2017. Available from: https://www.hain-lifescience.de/en/instructions-for-use.html [Accessed 1 March 2021].

15. Gatt N, Agius J, Ellul E. The prevalence, topography, and nature of Helicobacter pylori colonization in a Maltese population (abstract). Malta Med J 2009;21(Suppl):42.

16. Zammit D, Xerri T, Ellul P. Rapidity of diagnosis and management of $H$. pylori in the endoscopy unit at Mater Dei Hospital. Malta Med J 2017;3:6-14.

17. Burucoa C, Axon A. Epidemiology of Helicobacter pylori infection. Helicobacter 2017;22 Suppl 1:e12403.

18. Inoue M. Changing epidemiology of Helicobacter pylori in Japan. Gastric Cancer 2017;20:3-7.

19. Hirayama Y, Kawai T, Otaki J, Kawakami K, Harada Y. Prevalence of Helicobacter pylori infection with healthy subjects in Japan. $J$ Gastroenterol Hepatol 2014;24(Suppl 4):16-19.

20. Ji Z, Han F, Meng F, Tu M, Yang N, Zhang J. The association of age and antibiotic resistance of Helicobacter pylori: a study in Jiaxing city, Zhejiang Province, China. Medicine (Baltimore) 2016;95:e2831.

21. Uotani T, Graham DY. Diagnosis of Helicobacter pylori using the rapid urease test. Ann Transl Med 2015;3:9.

22. Wang YK, Kuo FC, Liu CJ, et al. Diagnosis of Helicobacter pylori infection: current options and developments. World J Gastroenterol 2015;21:11221-11235.

23. Shirin D, Matalon S, Avidan B, Broide E, Shirin H. Realworld Helicobacter pylori diagnosis in patients referred for esophagoduodenoscopy: the gap between guidelines and clinical practice. United European Gastroenterol J 2016;4:762-769.

24. Ramis IB, de Moraes EP, Fernandes MS, et al. Evaluation of diagnostic methods for the detection of Helicobacter pylori in gastric biopsy specimens of dyspeptic patients. Braz J Microbiol 2012;43:903-908.

25. Ghosh P, Bodhankar SL. Association of smoking, alcohol and NSAIDs use with expression of cag A and cag T genes of Helicobacter pylori in salivary samples of asymptomatic subjects. Asian Pac J Trop Biomed 2011;2:479-484.

26. Shamseya AM, Shamseya MM, Salem AM, Ahmed AM, Abdelfatah DA. Assessment of some health-related practices and knowledge among a group of Egyptian patients with peptic ulcer disease. J Med Sci Clin Res 2015;3:8186-8192.

27. Ogihara A, Kikuchi S, Hasegawa A, et al. Relationship between Helicobacter pylori infection and smoking and drinking habits. 
J Gastroenterol Hepatol 2000;15:271-276.

28. Smith S, Jolaiya T, Fowora M, et al. Clinical and socio-demographic risk factors for acquisition of Helicobacter pylori infection in Nigeria. Asian Pac J Cancer Prev 2018;19:1851-1857.

29. Itskoviz D, Boltin D, Leibovitzh $\mathrm{H}$, et al. Smoking increases the likelihood of Helicobacter pylori treatment failure. Dig Liver Dis 2017;49:764-768.

30. Public Health England. UK standards for microbiology investigations. Identification of Helicobacter species. ID 26, 2015. Available from: https://assets.publishing.service.gov. uk/government/uploads/system/uploads/attachment_data/ file/443464/ID_26i3.pdf [Accessed 1 March 2021].

31. Abebaw W, Kibret M, Abera B. Prevalence and risk factors of $H$. pylori from dyspeptic patients in northwest Ethiopia: a hospital based cross-sectional study. Asian Pac J Cancer Prev 2014;15:44594463.

32. Gao L, Weck MN, Stegmaier C, Rothenbacher D, Brenner H. Alcohol consumption, serum gamma-glutamyltransferase, and Helicobacter pylori infection in a population-based study among 9733 older adults. Ann Epidemiol 2010;20:122-128.

33. Pastukh N, Binyamin D, On A, Paritsky M, Peretz A. GenoType ${ }^{\circledR}$ HelicoDR test in comparison with histology and culture for Helicobacter pylori detection and identification of resistance mutations to clarithromycin and fluoroquinolones. Helicobacter 2017;22.

34. Binyamin D, Pastukh N, On A, Paritsky M, Peretz A. Phenotypic and genotypic correlation as expressed in Helicobacter pylori resistance to clarithromycin and fluoroquinolones. Gut Pathog 2017;9:48.

35. Francesco VD, Zullo A, Hassan C, Giorgio F, Rosania R, Ierardi E. Mechanisms of Helicobacter pylori antibiotic resistance: an updated appraisal. World J Gastrointest Pathophysiol 2011;2:35-41.

36. Savoldi A, Carrara E, Graham P, David Y, Conti M, Tacconelli E. Prevalence of antibiotic resistance in Helicobacter pylori: a systematic review and meta-analysis in World Health Organization regions. Gastroenterology 2018;155:1372-1382.e17.

37. Siddique O, Ovalle A, Siddique AS, Moss SF. Helicobacter pylori infection: an update for the internist in the age of increasing global antibiotic resistance. Am J Med 2018;131:473-479.

38. Malfertheiner P, Megraud F, O'Morain CA, et al; European Helicobacter Study Group. Management of Helicobacter pylori infection-the Maastricht IV/ Florence Consensus Report. Gut 2012;61:646-664.

39. Smith SM, O’Morain C, McNamara D. Antimicrobial susceptibility testing for Helicobacter pylori in times of increasing antibiotic resistance. World J Gastroenterol 2014;20:9912-9921.

40. Liou JM, Chen CC, Chang CY, et al; Taiwan Helicobacter Consortium. Efficacy of genotypic resistance-guided sequential therapy in the third-line treatment of refractory Helicobacter pylori infection: a multicentre clinical trial. J Antimicrob Chemother 2013;68:450-456.

41. Papastergiou V, Mathou N, Licousi S, et al. Seven-day genotypic resistance-guided triple Helicobacter pylori eradication therapy can be highly effective. Ann Gastroenterol 2017;31:198-204. 